\title{
The Effect of Continuous Positive Airway Pressure (CPAP) in Treatment of Patients with Refractory High Blood Pressure Associated with Severe Obstructive Sleep Apnea (OSA)
}

\author{
Anh Vo-Thi-Kim ${ }^{1}$, Bai Nguyen-Xuan ${ }^{2}$, Dung Dao-Van ${ }^{3}$ and Sy Duong-Quy ${ }^{4-6 *}$ \\ ${ }^{1}$ Nam Anh General Hospital, Binh Duong Province, Vietnam \\ ${ }^{2}$ Thai Binh University, Thai Binh Province, Vietnam \\ ${ }^{3}$ Central Committee of Communication and Education, Hanoi, Vietnam \\ ${ }^{4}$ Bio-Medical Research Center, Lam Dong Medical College, Dalat, Vietnam \\ ${ }^{5}$ Department of Cardio-Pulmonology Functional Testing, Cochin Hospital, Paris Descartes University, France \\ ${ }^{6}$ Division of Internal Medicine and Critical Care, Penn State College of Medicine, USA
}

\begin{abstract}
Introduction: Obstructive sleep apnea is very common in patients with high blood pressure (HBP), especially in whom with refractory HBP (R-HBP). It has been suggested treatment with continuous positive airway pressure (CPAP) might ameliorate the blood pressure in these patients. This study was planned to evaluate the effect of CPAP for treatment of R-HBP patients with severe OSA.

Methods: It was a cross-sectional and descriptive study. All patients with R-HBP associated with clinical symptoms of OSA were included in this study. They underwent polysomnography (PSG) for diagnosis severe OSA. The patients with severe OSA (apnea-hypopnea index (AHI) >30/hour) were treated with CPAP. They had been followed-up during 3 months.

Result: There was 48 patients with R-HBP and symptoms of OSA had PSG. Thirty-nine patients had severe OSA $(81.2 \%)$ and $32 / 39(82.1 \%)$ accepted to treat with CPAP. The mean age was $54 \pm 8$ years (45-64 years) with male-female ratio was 1.6; mean BMI was $27.5 \pm 4.6 \mathrm{~kg} / \mathrm{m} 2(23.2-32.5 \mathrm{~kg} / \mathrm{m} 2)$; mean systolic blood pressure (SBP) and diastolic blood pressure (DBP) were $160 \pm 15 \mathrm{mmHg}$ and $105 \pm 10 \mathrm{mmHg}$, respectively. Epworth score was 16 \pm 4 with AHI was $37 \pm 5$ /hour. There were a significant reduction of SBP and DBP before and after 3 months treated with CPAP $(P<0.01$ and $P<0.01$; respectively). Epworth score was significant lower after 3 months with CPAP than at inclusion $(P<0.01)$. Fasting glucose and total and $L D L$ cholesterol were significantly reduced after treatment with CPAP $(P<0.05$ and $P<0.05)$.
\end{abstract}

Conclusion: The prevalence of severe OSA is high in patients with R-HBP having clinical symptoms of OSA. This high prevalence is usually associated with overweight, a high risk factor for R-HBP and OSA. The treatment with CPAP might help to control of blood pressure in patients with R-HBP associated with severe OSA.

Keywords: High blood pressure; Refractory high blood pressure; Obstructive sleep apnea; Continuous positive airway pressure

\section{Introduction}

The prevalence of obstructive sleep apnea (OSA) is high in subjects with cardiovascular diseases. Previous studies showed that OSA has been associated with high blood pressure (HBP) in approximately $50 \%$ of cases, and vice versa, over $50 \%$ of subjects with HBP developed OSA $[1,2]$. In addition, these studies showed that there was a significant correlation the apnea-hypopnea index (AHI) diagnosed by polysomnography (PSG), and the severity of HBP. Moreover, HBP subjects with OSA had a higher risk of stroke than those without OSA [3-5].

The treatment of HBP is currently based on different classes of antihypertensive drugs as recommended by clinical guidelines to improve patient outcomes [6,7]. The pharmacologic treatment aims to lower systolic blood pressure (SBP) $<140 \mathrm{mmHg}$ and diastolic blood pressure (DBP) $<90 \mathrm{mmHg}$. However, in HBP patients with OSA, the goal of treatment is still unclear. Generally, for this special population (patients with HBP-OSA), the pharmacologic treatment should be optimal to prevent cardiovascular events during sleep and in long-term follow-up [8]. Especially, in HBP patients with severe OSA (AHI >30/ hour), the treatment option with antihypertensive drugs alone is not adequate and even though refractory in some patients $[9,10]$.
Therefore, the appropriate diagnosis and treatment of patients with refractory HBP (R-HBP) having severe OSA is still a real challenge in clinical practice for physicians to reduce the morbidity and mortality related to cardiovascular events $[11,12]$. The aim of our study was to evaluate the short-term effect of continuous positive airway pressure (CPAP) in treatment of patients with R-HBP and their adherence to this therapy.

\section{Materials and Methods}

\section{Patients}

All uncontrolled and treated patients with refractory HBP (had

*Corresponding author: Professor Sy Duong-Quy, MD, PhD, FCCP, Department of Cardio-Pulmonology Functional Testing, Cochin Hospital, Paris Descartes University, France, Tel: +0033679193377; E-mail: sduongquy.jfvp@gmail.com

Received July 24, 2017; Accepted August 08, 2017; Published August 16, 2017

Citation: Vo-Thi-Kim A, Nguyen-Xuan B, Dao-Van D, Duong-Quy S (2017) The Effect of Continuous Positive Airway Pressure (CPAP) in Treatment of Patients with Refractory High Blood Pressure Associated with Severe Obstructive Sleep Apnea (OSA). J Vasc Med Surg 5: 327. doi: 10.4172/2329-6925.1000327

Copyright: (c) 2017 Vo-Thi-Kim A, et al. This is an open-access article distributed under the terms of the Creative Commons Attribution License, which permits unrestricted use, distribution, and reproduction in any medium, provided the original author and source are credited. 
Citation: Vo-Thi-Kim A, Nguyen-Xuan B, Dao-Van D, Duong-Quy S (2017) The Effect of Continuous Positive Airway Pressure (CPAP) in Treatment of Patients with Refractory High Blood Pressure Associated with Severe Obstructive Sleep Apnea (OSA). J Vasc Med Surg 5: 327. doi: 10.4172/2329-6925.1000327

Page 2 of 4

been included in this study. They underwent polysomnography (PSG) at night to evaluate apnea-hypopnea index (AHI). For those with AHI $>30$ /hour, the treatment with CPAP was prescribed. Refractory HBP (R-HBP) was defined as HBP that required 4 or more medications for treatment as recommended [13]; uncontrolled R-HBP was defined as systolic blood pressure (SBP) $>140 \mathrm{mmHg}$ or diastolic blood pressure (DBP) $>90 \mathrm{mmHg}$ at rest under treatment. Inclusion criteria: all patients with uncontrolled R-HBP after use of 4 or more medications and having severe OSA were included in the present study. Exclusion criteria: patients with other comorbidities such as severe kidney failure, diabetes mellitus, and heart failure with NYHA stage 3-4 were excluded in this study.

\section{Methods}

It was a descriptive and cross-sectional study. The anthropometric and clinical and functional parameters were recorded for analysis. All study subjects underwent clinical examination, blood pressure measurement, PSG, and biochemical blood tests. They completed a screening questionnaire about symptoms of OSA, sleep habits, sleep quality, and snoring. The severity of sleepiness was assessed by Epworth (0-24 points) for each patient.

\section{Measure of blood pressure by sphygmanometer}

The blood pressure (BP) measured at rest was realized in all study subjects with the standard procedure recommended by American Heart Association (AHA) and described previously [14,15]. BP was measured by mercury sphygmanometer with the auscultatory (Korotkoff's sound) technique. All patient seated comfortably with back supported, legs uncrossed, and upper arm was supported at heart level with cuff bladder encircled $2 / 3$ of the circumference; cuff bladder was deflated at $2-3 \mathrm{~mm}$ per second; first and last audible sounds were recorded as systolic and diastolic pressure, respectively; neither the study subject nor the person taking the measurement could talk during the procedure.

\section{Measure of apnea-hypopnea index (AHI) by polysomnography (PSG)}

In-laboratory overnight PSG was performed for each study subject using Alice PSG (Philips, USA) as recommended by American Academy of Sleep Medicine and described previously [15-18]. The recording time was from $10 \mathrm{pm}$ to $6 \mathrm{am}$ of the day after. The recorded parameters were electroencephalography (EEG); chin electromyography (EMG); electrocardiography (ECG); air flows; thorax-abdomen movements; sleeping posture; apnea-hypopnea index (times/minutes); type of apnea (central apnea, obstructive apnea, or mixed apnea); mean oxygen saturation (SpO2), mean $\mathrm{SpO}_{2}$ with desaturation, and minimum $\mathrm{SpO} 2$ (nadir $\mathrm{SpO}_{2}$ ). The severity of OSA was defined by apnea - hypopnea index classified as mild OSA (AHI=5-15), moderate OSA (AHI=16$30)$, and severe OSA (AHI >30).

\section{Statistical analyses}

All study parameters were recorded and analyzed using IBMSPSS 22.0 software (Chicago, Illinois, USA). Values were expressed as mean \pm standard deviation (SD) for quantitative variables and percentage for qualitative variables. Normal distribution was tested by using the Skewness-Kurtosis manner. The comparison of quantitative parameters was done by Student's T test. P value $<0.05$ was considered as significant difference.

\section{Results}

Among 48 patients who had been diagnosed as refractory high blood pressure (R-HBP), there was 39/48 (81.2\%) patients had severe obstructive sleep apnea and $32 / 39(82.1 \%)$ patients accepted to treat with CPAP.

\section{Clinical characteristics of study patients}

The mean age of study patients with R-HBP was $54 \pm 8$ years (45-64 years; Table 1). The male-female ratio was 1.6. The mean BMI of study patients was $27.5 \pm 4.6 \mathrm{~kg} / \mathrm{m}^{2}\left(23.2-32.5 \mathrm{~kg} / \mathrm{m}^{2}\right.$; Table 1$)$. The mean neck and abdomen perimeters were $40 \pm 4 \mathrm{~cm}(35-44 \mathrm{~cm})$ and $86 \pm 9 \mathrm{~cm}(76$ $98 \mathrm{~cm}$ ), respectively (Table 1$)$. The mean systolic blood pressure (SBP) and diastolic blood pressure (DBP) were $160 \pm 15$ (150-180) $\mathrm{mmHg}$ and $105 \pm 10$ (95-115) $\mathrm{mmHg}$, respectively (Table 1). Epworth score of study patients with R-HBP and OSA was $16 \pm 4$ (12-22).

\section{Functional and biochemical characteristics of study patients}

Lung function parameters of study patients were in normal limits except there was a mild reduction of total lung capacity (TLC $=84 \pm$ 9\% (74-95\%); Table 2). The results of polysomnography (PSG) showed mean apnea-hypopnea index was $37 \pm 5$ (31-43)/hour with mean $\mathrm{SpO}_{2}$ was $92 \pm 3 \%(88-95 \%)$ and nadir $\mathrm{SpO}_{2}$ was $83 \pm 6 \%$ (77-89\%) (Table 2).

\begin{tabular}{|l|c|c|}
\hline \multirow{2}{*}{ Values } & \multicolumn{2}{|c|}{ Study patients (N=32) } \\
\cline { 2 - 3 } & Mean \pm SD & Min-Max \\
\hline Anthropometric parameters & & $45-64$ \\
\hline Age, years & $54 \pm 8$ & - \\
\hline Male/Female, ratio & 1.6 & $156-174$ \\
\hline Height, $c m$ & $164 \pm 8$ & $56-82$ \\
\hline Weight, $\mathrm{kg}$ & $68 \pm 11$ & $23.2-32.5$ \\
\hline BMI, $\mathrm{kg} / \mathrm{m}^{2}$ & $27.5 \pm 4.6$ & $35-44$ \\
\hline Neck perimeter, $\mathrm{cm}$ & $40 \pm 4$ & $76-98$ \\
\hline Abdomen perimeter, $\mathrm{cm}$ & $86 \pm 9$ & $150-180$ \\
\hline Blood pressure & & $95-115$ \\
\hline SBP, $m m H g$ & $160 \pm 15$ & \\
\hline DBP, $m m H g$ & $105 \pm 10$ & $12-22$ \\
\hline Daytime sleepiness & & \\
\hline Epworth score, $(0-24)$ & $16 \pm 4$ & \\
\hline
\end{tabular}

R-HBP: Refractory High Blood Pressure; OSA: Obstructive Sleep Apnea; BMI Body Mass Index; SBP: Systolic Blood Pressure; DBP: Diastolic Blood Pressure.

Table 1: Clinical characteristics of study patients with R-HBP and OSA.

\begin{tabular}{|l|c|c|}
\hline \multirow{2}{*}{ Parameters } & \multicolumn{2}{|c|}{ Study patients (N=32) } \\
\cline { 2 - 3 } & Mean \pm SD & Min-Max \\
\hline Lung function test & $94 \pm 8$ & $90-103$ \\
\hline FEV $_{1}, \%$ & $96 \pm 7$ & $91-105$ \\
\hline FVC, $\%$ & $77 \pm 5$ & $72-84$ \\
\hline FEV $/$ /FVC, \% & $84 \pm 9$ & $74-95$ \\
\hline TLC, $\%$ & & \\
\hline Polysomnography & $37 \pm 5$ & $31-43$ \\
\hline AHI, times/hour & $92 \pm 3$ & $88-95$ \\
\hline Mean SpO,$\%$ & $83 \pm 6$ & $77-89$ \\
\hline Nadir SpO,$\%$ & & \\
\hline Biological test & $128 \pm 7$ & $120-138$ \\
\hline Glucose, $m g / d L$ & $6.8 \pm 0.7$ & $5.2-7.6$ \\
\hline Total cholesterol, $m m o l / L$ & $184 \pm 37$ & $142-226$ \\
\hline LDL cholesterol, $\mathrm{mg} / \mathrm{dL}$ & $176 \pm 22$ & $154-198$ \\
\hline Triglycerides, $\mathrm{mg} / \mathrm{dL}$ & $1.3 \pm 0.4$ & $0.8-1.7$ \\
\hline Creatinine, $g / d L$ & $0.35 \pm 0.14$ & $0.22-0.48$ \\
\hline Uric acid, $\mathrm{mmol} / \mathrm{L}$ & & \\
\hline
\end{tabular}

FEV1: Forced Expiratory Volume in one Second; FVC: Forced Vital Capacity; TLC Total Lung Capacity; AHI: Apnea-Hypopnea Index; LDL: Low-Density Lipoprotein.

Table 2: Functional and biochemical characteristics of study patients. 
Citation: Vo-Thi-Kim A, Nguyen-Xuan B, Dao-Van D, Duong-Quy S (2017) The Effect of Continuous Positive Airway Pressure (CPAP) in Treatment of Patients with Refractory High Blood Pressure Associated with Severe Obstructive Sleep Apnea (OSA). J Vasc Med Surg 5: 327. doi: 10.4172/2329-6925.1000327

Page 3 of 4

The results of biochemical blood test showed there was a mild increase of glucose, total and LDL cholesterol, and triglycerides $(128 \pm 7 \mathrm{mg} / \mathrm{dL}$, $6.8 \pm 0.7 \mathrm{mmol} / \mathrm{L}, 184 \pm 37 \mathrm{mg} / \mathrm{dL}$, and $176 \pm 22 \mathrm{mg} / \mathrm{dL}$; respectively; Table 2).

\section{Clinical, functional, and biochemical characteristics of study patients after CPAP treatment}

The results of present study for patients with R-HBP and OSA treated with continuous positive airway pressure (CPAP) showed there were no significant differences for anthropometric parameters (BMI and neck and abdomen perimeters) before and after 3 months with CPAP (Table 3). There were significantly different for systolic blood pressure (SBP) and diastolic blood pressure (DBP) before and after 3 months treated with CPAP $(160 \pm 15 \mathrm{mmHg}$ vs. $135 \pm 10$ and $105 \pm 10$ vs. $85 \pm 5 ; \mathrm{P}<0.01$ and $\mathrm{P}<0.01$; respectively; Table 3). Epworth score was significant lower after 3 months with CPAP than at inclusion (10 \pm 6 vs. $16 \pm 4$; $\mathrm{P}<0.01$; Table 3 ).

There was any significant difference for lung function parameters before and after 3 months with CPAP treatment. After 3 months treated with CPAP, there was a significant reduction of fasting glucose and total and LDL cholesterol in compare to that at inclusion $(112 \pm$ $12 \mathrm{mg} / \mathrm{dL}$ vs. $128 \pm 10 \mathrm{mg} / \mathrm{dL}, 5.9 \pm 0.8 \mathrm{mmol} / \mathrm{L}$ vs. $6.8 \pm 0.7 \mathrm{mmol} / \mathrm{L}$, and $162 \pm 26 \mathrm{mg} / \mathrm{dL}$ vs. $184 \pm 37 \mathrm{mg} / \mathrm{dL} ; \mathrm{P}<0.05, \mathrm{P}<0.05$, and $\mathrm{P}$ $<0.05$; respectively; Table 3 ). There were no significant differences of triglycerides, creatinine, and uric acid before and after treatment with CPAP $(\mathrm{P}>0.05, \mathrm{P}>0.05$, and $\mathrm{P}>0.05$; respectively; Table 3 ).

\section{Discussion}

The results of present study showed that

- Percentage of severe OSA in R-HBP was $81.2 \%$;

\begin{tabular}{|c|c|c|c|}
\hline \multirow[t]{2}{*}{ Parameters } & \multicolumn{2}{|c|}{ Study patients $(\mathrm{N}=32)$} & \multirow[t]{2}{*}{$\mathbf{P}$} \\
\hline & Before CPAP & After CPAP & \\
\hline \multicolumn{4}{|c|}{ Anthropometric parameters } \\
\hline $\mathrm{BMI}, \mathrm{kg} / \mathrm{m}^{2}$ & $27.5 \pm 4.6$ & $26.4 \pm 4.7$ & NS \\
\hline Neck perimeter, $\mathrm{cm}$ & $40 \pm 4$ & $40 \pm 5$ & NS \\
\hline Abdomen perimeter, $\mathrm{cm}$ & $86 \pm 9$ & $84-10$ & NS \\
\hline \multicolumn{4}{|l|}{ Blood pressure } \\
\hline $\mathrm{SBP}, \mathrm{mmHg}$ & $160 \pm 15$ & $135 \pm 10$ & $<0.01$ \\
\hline $\mathrm{DBP}, \mathrm{mmHg}$ & $105 \pm 10$ & $85 \pm 5$ & $<0.01$ \\
\hline \multicolumn{4}{|l|}{ Daytime sleepiness } \\
\hline Epworth score, (0 -24) & $16 \pm 4$ & $10 \pm 6$ & $<0.01$ \\
\hline \multicolumn{4}{|l|}{ Lung function test } \\
\hline FEV1, \% & $94 \pm 8$ & $93 \pm 7$ & NS \\
\hline FVC, \% & $96 \pm 7$ & $96 \pm 8$ & NS \\
\hline FEV1/FVC, $\%$ & $77 \pm 5$ & $76 \pm 6$ & NS \\
\hline TLC, $\%$ & $84 \pm 9$ & $86 \pm 10$ & NS \\
\hline \multicolumn{4}{|l|}{ Biological test } \\
\hline Glucose, $m g / d L$ & $128 \pm 10$ & $112 \pm 12$ & $<0.05$ \\
\hline Total cholesterol, $\mathrm{mmol} / \mathrm{L}$ & $6.8 \pm 0.7$ & $5.9 \pm 0.8$ & $<0.05$ \\
\hline LDL cholesterol, mg/dL & $184 \pm 37$ & $162 \pm 26$ & $<0.05$ \\
\hline Triglycerides, $\mathrm{mg} / \mathrm{dL}$ & $176 \pm 22$ & $169 \pm 25$ & NS \\
\hline Creatinine, $g / d L$ & $1.3 \pm 0.4$ & $1.2 \pm 0.5$ & NS \\
\hline Uric acid, $\mathrm{mmol} / \mathrm{L}$ & $0.35 \pm 0.14$ & $0.37 \pm 0.12$ & NS \\
\hline
\end{tabular}

CPAP: Continuous Positive Airway Pressure; BMI: Body Mass Index; SBP: Systolic Blood Pressure; DBP: Diastolic Blood Pressure; FEV1: Forced Expiratory Volume in one Second; FVC: Forced Vital Capacity; TLC: Total Lung Capacity; AHI: Apnea-Hypopnea Index; LDL: Low-Density Lipoprotein.

Table 3: Clinical, functional, and biochemical characteristics of study patients after CPAP treatment.
- Patients with R-HBP and OSA had also increased glucose and total and LDL cholesterol;

- R-HBP patients with severe OSA treated with CPAP had a significant reduction of blood pressure.

The high prevalence of OSA in patients with HBP has been reported previously [19-21]. This high prevalence is due to both diseases, HBP and OSA, share common risk factors such as overweight. Generally, overweight is frequent in subjects with HBP and in whom with OSA. However, the mechanism by which overweight develops OSA is different from what in HBP [22]. In subjects with obesity, overweight is always associated with high risk factor for OSA, due to the partial or total collapse of upper-airways during sleep. In the present study, patients having R-HBP were overweight (Table 1). They also had clinical symptom of OSA manifested by daytime sleepiness evaluated by Epworth score. In this study, $81.2 \%$ of patients with R-HBP had severe OSA. This high prevalence of severe OSA in these study patients suggests OSA should be screened in patients with R-HBP.

Beside clinical symptoms of OSA evaluated indirectly by daytime sleepiness via Epworth score, study patients had the features of metabolic syndrome with increasing fasting glucose and LDL cholesterol (Table 2). These features are also seen in subjects with HBP. In the present study, $82.1 \%$ of patients with R-HBP and severe OSA had been treated with CPAP and had an excellent adherence and tolerance. Especially, after 3 months, the means of systolic blood pressure (SBP) and diastolic blood pressure were significantly decreased and normalized in study patients (Table 3). This result suggests that CPAP might be an addon treatment for patients with R-HBP and OSA. However, until now, there are no recommendations for the level of OSA severity should be treated with CPAP in patients with R-HBP. Moreover, the present study demonstrated that treatment with CPAP also reduced the level of fasting glucose and cholesterol in study subjects (Table 3 ).

Eventually, the effect of CPAP on metabolic syndrome has been demonstrated by previous studies [23]. The metabolic syndrome is also known as the consequence of OSA, related to oxidative stress producing by intermittent hypoxia during sleep [24]. The intermittent hypoxia is also the cause of diurnal HBP in subjects with OSA and it is due to sympathetic activity releasing on walk up. That why in some cases, treatment with CPAP might normalize blood pressure in subjects with OSA associated with HBP. The present study showed that treatment with CPAP in short-term follow-up (3 months) had a positive effect on R-HBP. This result suggests CPAP might be recommended for patients with R-HBP associated with severe OSA diagnosed by polysomnography (PSG). In patients with R-HBP having clinical symptom of OSA, PSG or respiratory polygraphy should be done routinely for screening severe OSA. However, due to a small number of study patients and with a short-term follow-up, the present study has some limitations related to the statistical methodology and subgroup analyses. More studies about the role of CPAP in R-HBP should be necessary in the future.

\section{Conclusion}

OSA is very common in patients with refractory high blood pressure (R-HBP). The screening of severe OSA in patients with R-HBP should be done systematically in daily practice, especially for patients with clinical symptoms of OSA. The treatment with CPAP in patients with R-HBP and severe OSA might reduce significantly blood pressure.

\section{Conflict of Interest}

The authors declare no conflict of interest. 
Citation: Vo-Thi-Kim A, Nguyen-Xuan B, Dao-Van D, Duong-Quy S (2017) The Effect of Continuous Positive Airway Pressure (CPAP) in Treatment of Patients with Refractory High Blood Pressure Associated with Severe Obstructive Sleep Apnea (OSA). J Vasc Med Surg 5: 327. doi: 10.4172/2329-6925.1000327

\section{Acknowledgements}

The authors would like to thank all the Member of Clinical Research Unit of Lam Dong Medical College for their contribution to this work.

\section{References}

1. Bassetti CL, Milanova M, Gugger M (2006) Sleep-disordered breathing and acute ischemic stroke: diagnosis, risk factors, treatment, evolution, and longterm clinical outcome. Stroke 37: 967-972.

2. Peker $\mathrm{Y}$, Carlson J, Hedner $\mathrm{J}$ (2006) Increased incidence of coronary artery disease in sleep apnoea: a long-term follow-up. Eur Respir J 28: 596-602.

3. Davies CW, Crosby JH, Mullins RL, Barbour C, Davies RJ, et al. (2000) Casecontrol study of 24 hour ambulatory blood pressure in patients with obstructive sleep apnoea and normal matched control subjects. Thorax 55: 736-740.

4. Gami AS, Howard DE, Olson EJ, Somers VK (2005) Day-night pattern of sudden death in obstructive sleep apnea. N Engl J Med 352: 1206-1214.

5. Gami AS, Somers VK (2008) Implications of obstructive sleep apnea for atria fibrillation and sudden cardiac death. J Cardiovasc Electrophysiol 19: 997-1003.

6. James PA, Oparil S, Carter BL, Cushman WC, Dennison-Himmelfarb C, et al. (2014) 2014 Evidence-Based Guideline for the Management of High Blood Pressure in Adults Report From the Panel Members Appointed to the Eighth Joint National Committee (JNC 8). JAMA 311: 507-520.

7. Chobanian AV, Bakris GL, Black HR, Cushman WC, Green LA, et al. (2003) The seventh report of the Joint National Committee on Prevention, Detection, Evaluation, and Treatment of High Blood Pressure: the JNC 7 report. JAMA 289: $2560-2572$

8. Wolf J, Narkiewicz K (2017) Optimizing the management of uncontrolled/ resistant hypertension. The importance of sleep apnoea syndrome. Curr Vasc Pharmacol.

9. Rao M, Rajda G, Uppuluri S, Beck GR, Liu L, et al. (2010) The role of continuous positive airway pressure in the treatment of hypertension in patients with obstructive sleep apnea-hypoapnea syndrome: a review of randomized trials. Rev Recent Clin Trials 5: 35-42.

10. Chin K, Nakamura T, Takahashi K, Sumi K, Matsumoto H, et al. (2006) Falls in blood pressure in patients with obstructive sleep apnoea after long-term nasa continuous positive airway pressure treatment. J Hypertens 24: 2091-2099.

11. Pedrosa RP, Drager LF, de Paula LKG, Amaro ACS, Bortolotto LA, et al. (2013) Effects of OSA treatment on BP in patients with resistant hypertension: a randomized trial. Chest 144: 1487-1494.

12. Isaksson $\mathrm{H}$, Ostergren $\mathrm{J}$ (1994) Prognosis in therapy-resistant hypertension. J Intern Med 236: 643-649.
13. Calhoun DA, Jones D, Textor S, Goff DC, Murphy TP, et al. (2008) Resistant hypertension: diagnosis, evaluation, and treatment. A scientific statement from the American Heart Association Professional Education Committee of the Council for High Blood Pressure Research. Hypertension 51: 1403-1419.

14. Smith L (2005) New AHA Recommendations for Blood Pressure Measurement. Am Fam Physician 72: 1391-1398.

15. Epstein LJ, Kristo D, Strollo PJ, Friedman N, Malhotra A, et al. (2009) Adult Obstructive Sleep Apnea Task Force of the American Academy of Sleep Medicine. Clinical guideline for the evaluation, management and long-term care of obstructive sleep apnea in adults. J Clin Sleep Med 5: 263-276.

16. Duong-Quy S, Tran-Phi D, Nguyen-Thi-Hong L, Tang-Thi-Thao T, Ho-VietThuy D, et al. (2016) Prevalence and Characteristic of Obstructive Sleep Apnea Syndrome in Subjects with High Blood Pressure: A Pilot Study in Vietnam. J Vasc Med Surg 4: 273

17. Tran-Van H, Vo-Thi-Kim A, Duong-Quy S (2017) The Study of Correlation between Diurnal Blood Pressure with Nocturnal Oxygen Desaturation and Nitrite Production in Subjects with Obstructive Sleep Apnea (OSA). J Vasc Med Surg 5: 317.

18. Duong-Quy S, Thong Hua-Huy, Huyen-Tran Tran-Mai-Thi, Nhat-Nam LeDong, Timothy J. Craig, et al. (2016) Study of Exhaled Nitric Oxide in Subjects with suspected Obstructive Sleep Apnea: A Pilot Study in Vietnam. Pulmonary Medicine.

19. Drager LF, Genta PR, Pedrosa RP, Nerbass FB, Gonzaga CC, et al. (2010) Characteristics and predictors of obstructive sleep apnea in patients with systemic hypertension. Am J Cardiol; 105: 1135-1139.

20. Marin JM, Agusti A, Villar I, Forner M, Nieto D, et al. (2012) Association between treated and untreated obstructive sleep apnea and risk of hypertension. JAMA 307: 2169-2176.

21. Lavie P, Herer P, Hoffstein V (2000) Obstructive sleep apnoea syndrome as a risk factor for hypertension: population study. BMJ 320: 479-482.

22. Vgontzas AN, Bixler EO, Basta M (2010) Obesity and sleep: a bidirectiona association? Sleep 2010 33: 573-574

23. Drager LF, Pedrosa RP, Diniz PM, Diegues-Silva L, Marcondes B, et al. (2011) The effects of continuous positive airway pressure on prehypertension and masked hypertension in men with severe obstructive sleep apnea. Hypertension 57: 549-555.

24. Kong DL, Qin Z, Wang W, Pan Y, Kang J, et al. (2016) Association between obstructive sleep apnea and metabolic syndrome: a meta-analysis. Clin Invest Med 39: E161-E172. 